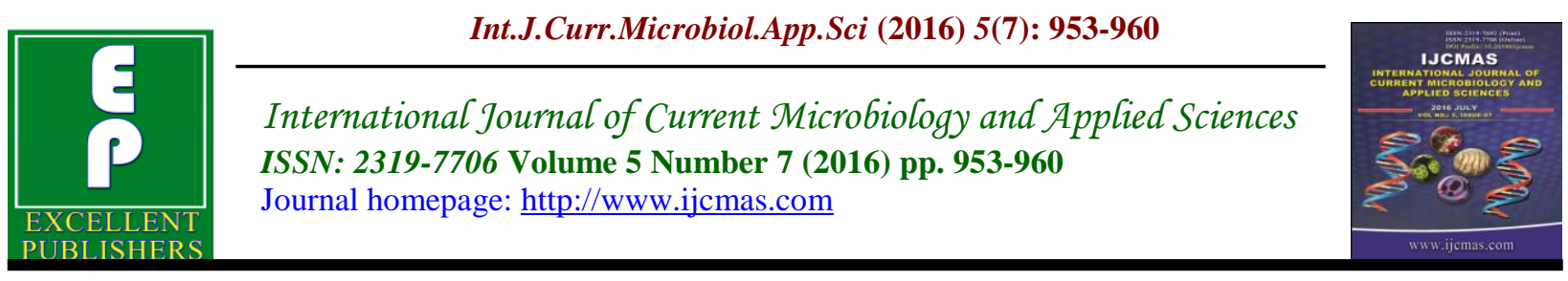

Original Research Article

http://dx.doi.org/10.20546/ijcmas.2016.507.107

\title{
Microbial Production of 1, 3-Propanediol using Newly Isolated Enterobacter cloacae GNTEW13-1, GNTEW13-V and its Enhancement Studies by UV Mutagenesis
}

\author{
Tathagat Waghmare* and G.R. Naik \\ Department of Biotechnology, Gulbarga University, Gulbarga, Karnataka, India.-585106 \\ *Corresponding author
}

\begin{tabular}{|c|c|}
\hline & A B S T R A C T \\
\hline Keywords & \multirow{4}{*}{$\begin{array}{l}\text { The crude glycerol has been converted to 1, 3-propanediol which is not only } \\
\text { a useful final product but also a valuable starting compound for producing } \\
\text { polymers, A newly isolated Enterobacter cloacae GNTEW13-1 and } \\
\text { GNTEW13-V has shown a high produciblility of 1, 3-propanediol by using } \\
\text { biofuel derived crude glycerol as a sole carbon and energy source. In the } \\
\text { preliminary stage the Enterobacter cloacae GNTEW13-1 and GNTEW13-V } \\
\text { has grown on the glycerol based medium to enhance the more utilization of } \\
\text { glycerol for the high production 1, 3-propanediol. Total } 10 \text { mutants were } \\
\text { screened after UV Treatment and among these mutants, } 3 \text { mutants showed } \\
\text { increased production over parent strains. }\end{array}$} \\
\hline $\begin{array}{l}\text { Crude Glycerol, } \\
\text { 1, 3-propanediol, } \\
\text { Enterobacter } \\
\text { cloacae, } \\
\text { Mutagenesis. }\end{array}$ & \\
\hline Article Info & \\
\hline $\begin{array}{l}\text { Available Online: } \\
10 \text { July } 2016\end{array}$ & \\
\hline
\end{tabular}

\section{Introduction}

Worldwide the global interest is being directed towards research and commercialization of several microbial fermentation technologies for chemical production. 1, 3-propanediol is one of the oldest known fermentation products. It was reliably identified as early 1881 by August Freund, in glycerol fermenting mixed culture containing Clostridium pasteurianum as the active organism (Freund, 1881). Later in 1914, Viosenet described a wine spoiling Bacillus that produced the substance. Quantitative analysis of 1, 3-propanediol produced by different Enterobacteria had started at the microbiology school of Delf and was successfully continued at Ames, Iowa (Mickelson and Werkman, 1940) In the 1960s, Interest shifted to the Glycerol attacking enzymes, in particular to the glycerol and dioldehydratase, as these enzymes were peculiar in the 1, 3propanediol synthesis pathway. 1, 3propanediol forming clostridia were first described in 1983 as part of a process to obtain a special product from glycerol excreting algae (Nakas et al., 1983).

The need for sustainable resource supply, the rapid advances in biotechnology and microbial genetics and the strategic shift of major chemical companies into the area of 
life sciences are some of the driving forces for renewed interest in producing bulk chemicals from renewable resources by biological process. The Biotechnological synthesis of 1, 3-propanediol appears to be an attractive alternative to chemical synthesis as it is carried out under milder operational conditions, and it does not generate toxic products. Considering the yield product recovery and environmental protection, much attention has been paid to microbial production of 1,3-propanediol (Xiu et al., 2007). Moreover the microbial process can use glycerol as substrate, which is low-cost renewable resource appearing in increasing quantities as the principal byproduct from fat saponification, alcoholic beverage manufacture and biodiesel production units. Glycerol is not only cheap and abundant, but its greater degree of reduction than sugars offers the opportunity to obtain reduced chemicals at higher yields than those obtained using sugars (Dharmadi et al., 2006).

1, 3-propanediol is a typical product of glycerol fermentation and has not been found in the fermentative conversion of other organic substrates. Only very few organisms, all of them bacteria, are able to form it (Biebl et al., 1999). A number of microorganisms can ferment sugars to glycerol but they cannot convert glycerol to 1, 3-propanediol. Others may have the ability to ferment glycerol to 1, 3propanediol and still others can ferment mixtures of glycerol and sugars to 1, 3-PDO, however, none, can ferment sugars directly to 1, 3-PDO (Cameron et al., 1998). There are reports where new metabolic pathways have been designed in cells by combining the ability to ferment sugar to glycerol and subsequently glycerol to 1, 3-PDO (Forage and Lin 1982; Tong and Cameron, 1992).

The biotechnological production of 1, 3PDO from glycerol has been demonstrated for several bacteria, such as Klebsiella, Clostridia, Citrobacter, Enterobacter and Lactobacilli (Sauer et al., 2008). Several Clostridial species suc as non pathogenic Clostridium butyricum (Papanikolaou et al., 2004), C. pasteurianum (Biebl, 2001) grow on glycerol and form 1, 3-PDO. Although it might be easier to handle facultative anaerobes, but since all these strains are classified as opportunistic pathogens, special safety precautions are required to grow them. Along with $K$. pneumonia, other species of same genera have also been exploited for 1,3-PDO production, such as L.oxutoca (Homann et al., 1990; Yang et al., 2007) and K.planticola (Homann et al., 1990). Lactobacillus brevis, L.buchneri and L. reuteri (Peng et al., 2002) have been shown to use glycerol as an external hydrogen acceptor source during fermentation.

\section{Materials and methods}

\section{Collection of Sample}

The biofuel derived crude glycerol was obtained from the biofuel information and demonstration unit established by the Karnataka State Biofuel Development Board, at the department of Biotechnology Gulbarga University, Gulbarga, Karnataka India.

\section{Microorganism}

In the Process of converting crude glycerol to 1, 3-Propanediol the Enterobacter Cloacae GNTEW-13-1 and GNTEW-13-V, which are previously isolated by us in our laboratory (Waghmare and Naik, 2015), was stored in the department of Biotechnology Gulbarga University, Gulbarga, Karnataka, India. Later the isolated strain was grown on the different concentration $(1 \%, 2 \%, 5 \%$, $10 \%, 15 \%$ \& $20 \%$ of glycerol based medium. 


\section{Culture medium}

The strain was maintained in LB agar Medium containing 5\% Crude Glycerol in culture tube at $4^{\circ} \mathrm{C}$. Pre-cultures of pure culture inoculums were cultivated in Hungate test tubes in an appropriate 1, 3Propanediol production medium $\left(37^{\circ} \mathrm{C}, 18\right.$ h).

\section{Fermentation medium}

The composition of the fermentation medium was $(\%, \mathrm{w} / \mathrm{v})$ : glycerol-2.0, $\mathrm{K}_{2} \mathrm{HPO}_{4-} .0069, \mathrm{KH}_{2} \mathrm{PO} 4-0.025,\left(\mathrm{NH}_{4}\right)_{2} \mathrm{SO}_{4}-$ $0.4, \mathrm{MgSO}_{4} .7 \mathrm{H}_{2} \mathrm{O}-0.02$, yeast extract-0.15 and $1.0 \mathrm{ml}$ of trace elements solution. The composition of trace elements was $(\%, \mathrm{w} / \mathrm{v})$ : $\mathrm{MnSO}_{4} .4 \mathrm{H}_{2} \mathrm{O}-0.01$, $\mathrm{ZnCl}_{2}-0.007$, $\mathrm{Na}_{2} \mathrm{MoO}_{4} .2 \mathrm{H}_{2} \mathrm{O}-0.003, \quad \mathrm{H}_{3} \mathrm{BO}_{3}-0.006$, $\mathrm{CoCl}_{2} .6 \mathrm{H}_{2} \mathrm{O}-0.02, \quad \mathrm{CuSO}_{4} .5 \mathrm{H}_{2} \mathrm{O}-0.002$, $\mathrm{NiCl}_{2} .5 \mathrm{H}_{2} \mathrm{O}-0.002,0.2 \mathrm{ml} \mathrm{FeSO}_{4}$ solution (Hao et al., 2008). The composition ferrous sulfate solution was (\%w/v): $\mathrm{FeSO}_{4} \cdot 7 \mathrm{H}_{2} \mathrm{O}$ 0.5.The fermentation medium was supplemented with biofuel derived crude glycerol at a concentration of $20.0 \pm 1.0 \mathrm{~g} / \mathrm{L}$. The crude glycerol composition was (w/w) $90.5 \%$ glycerol, $7 \% \mathrm{NaCl}, 10.11 \%$ moisture, and $\mathrm{pH}$ 6.5. The media were autoclaved $\left(121^{\circ} \mathrm{C}, 20 \mathrm{~min}.\right)$.

\section{Experimental Methodology}

The strain was maintained at $4{ }^{\circ} \mathrm{C}$ on $\mathrm{LB}$ medium. For inoculums, cells were cultivated at $30{ }^{\circ} \mathrm{C}$ in a rotary shaker at 120 rpm using $100 \mathrm{ml}$ anaerobic flasks containing $50 \mathrm{ml}$ of $2 \%$ glycerol based LB medium. $5 \mathrm{ml}$ of inoculums has been added in to the $50 \mathrm{ml}$ production medium. Further these flasks are shaken generally by a gyratory shaker at $200-250 \mathrm{rpm}$. at $37^{\circ} \mathrm{C}$ temperature. The sample has been collected at every 24 hours of time interval followed by $\mathrm{pH}$ measurement for the quantification of
1, 3-propanediol production and other byproducts. The experiment was performed in duplicate.

\section{1, 3-PDO Production by UV mutants}

A $8 \mathrm{ml}$ of bacterial suspension taken in an aseptic Petri-plate without cover was exposed to UV light for 5 to 60 minutes at a distance of $40 \mathrm{~cm}$ from UV lamp with a wavelength of $2537 \mathrm{~A}^{\circ}$ and a power of $30 \mathrm{~W}$ to get $96 \%$ lethality. Number of mutants obtained during mutagenesis was shown in Table .1. Total 10 mutants were screened after UV Treatment and among these mutants, 3 mutants showed increased production over parent strains. From the above three mutants, UV-2 and UV-4 Mutants were resulted from $20 \mathrm{~min}$ UV exposure. And the remaining one mutant UV-6 was obtained from $30 \mathrm{~min}$ UV exposure. 1, 3-PDO production by UVMutants in comparison with parent strain was shown in table 2.

UV Mutant 6 had shown the maximum 1, 3PDO production of $16.8 \mathrm{mg} / \mathrm{ml}$ over the parent strain $(15.01 \mathrm{mg} / \mathrm{ml})$. The molar yield $(0.21 \mathrm{~mol} / \mathrm{mol})$ and productivity $(0.15 \mathrm{~g} / \mathrm{L} / \mathrm{H})$.

\section{Analytical Methods}

\section{Determination of bacterial growth}

Growth was followed by optical density measured at $600 \mathrm{~nm}$ and O.D. values were converted to cell dry weight per volume (mg $\mathrm{dw} \cdot \mathrm{mL}-1)$

\section{Analysis of the fermented production medium}

1, 3-PDO, 2, 3-butanediol and glycerol content were analyzed by high performance liquid chromatography (Waters $\circledR$ ). It was used column Aminex ${ }^{\circledR}$ HPX-87H, 300 x 7.8 
mm (Bio-Rad Laboratories Ltd) and precolumn (Bio-Rad Laboratories Ltd), IR detector (Waters 2414), binary pump (Waters 1525), furnace and temperature controller module (Waters) chromatographic software: Breeze. $0.005 \mathrm{M} \mathrm{H}_{2} \mathrm{SO}_{4}$ act as a mobile phase with flow rate $0.5 \mathrm{ml} / \mathrm{min}$ and Injection volume was $20 \mu 1,65^{\circ} \mathrm{C}$ as working temperature.

\section{Results and Discussion}

Enterobacter cloacae GNTEW-13-1 \& GNTEW 13-V was found to be a potent 1, 3propanediol producer by utilizing a biofuel derived crude glycerol as a sole carbon source. It was evaluated that almost all biofuel derived crude glycerol was consumed with the final cell concentration observed to be approximately $1.8 \mathrm{~g} \cdot \mathrm{L}-1$.

Table.1 Number of mutants obtained during UV Mutagenesis

\begin{tabular}{|c|c|}
\hline Time duration of UV Mutagenesis & Number of Colonies (CFU/ml \\
\hline Parent & 300 \\
\hline $5 \mathrm{Min}$ & 35 \\
\hline $10 \mathrm{~min}$ & 27 \\
\hline $20 \mathrm{~min}$ & 18 \\
\hline $30 \mathrm{~min}$ & 2 \\
\hline $40 \mathrm{~min}$ & 1 \\
\hline $50 \mathrm{Min}$ & - \\
\hline $60 \mathrm{~min}$ & - \\
\hline
\end{tabular}

Table.2 1, 3-PDO production by UV-Mutants in comparison with parent strain

\begin{tabular}{|c|c|}
\hline UV Mutants & 1,3-Propanediol mg/ml \\
\hline Parent strain & 15.0 \\
\hline UV-1 & 11.5 \\
\hline UV-2 & 16.5 \\
\hline UV-3 & 14.7 \\
\hline UV-4 & 16.2 \\
\hline UV-5 & 9.0 \\
\hline UV-6 & 16.8 \\
\hline UV-7 & 10.0 \\
\hline UV-8 & 10.7 \\
\hline UV-9 & 11.1 \\
\hline UV-10 & 13.0 \\
\hline
\end{tabular}


Fig.1 Metabolic pathways of glycerol metabolism (Zeng and Biebl, 2002)

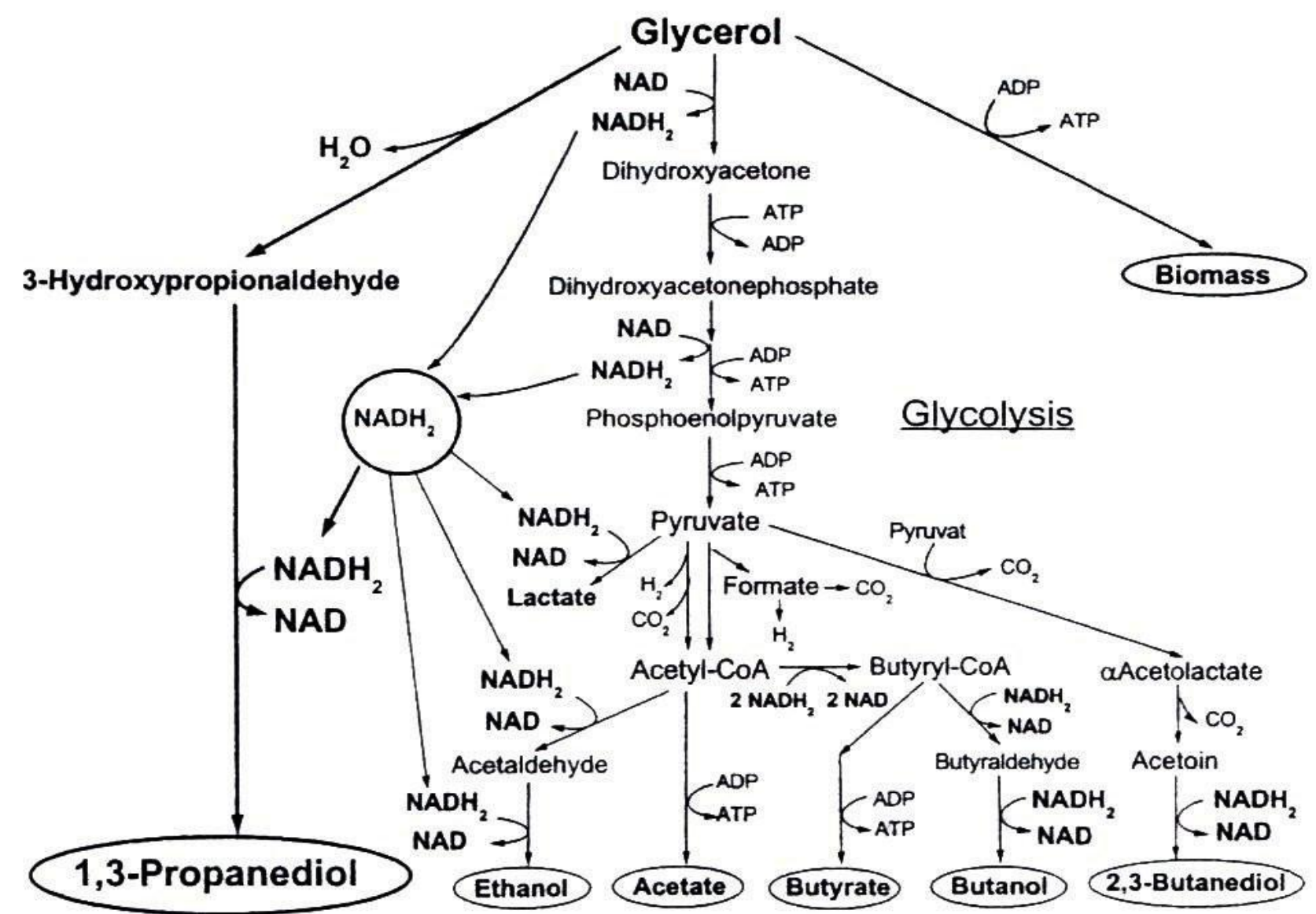

Fig.2 Bar chart showing the production of 1, 3-propanediol by UV-Mutants

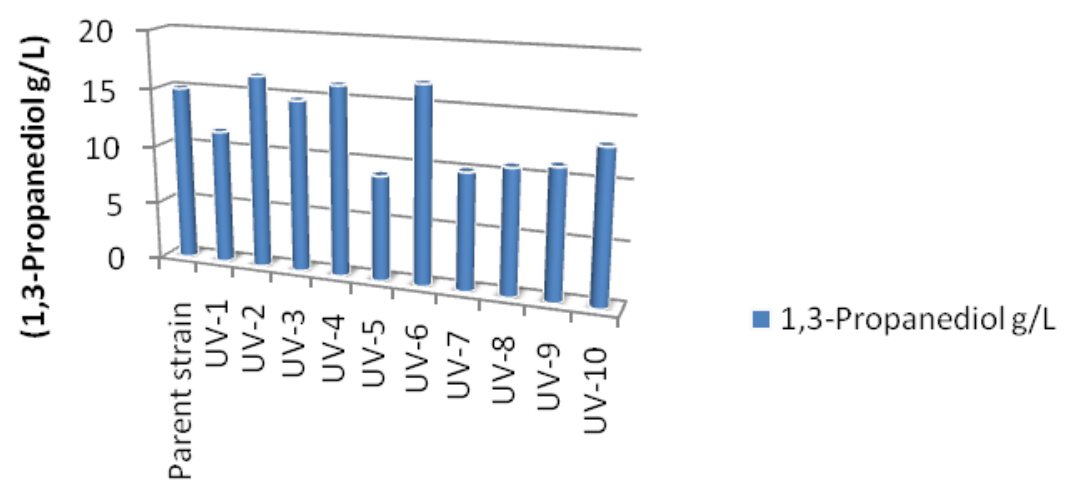

(UV-Mutants) 
Fig.3 HPLC chromatographic peak showing the production of 1, 3-propanediol by Enterobacter cloacae GNTEW-13-1

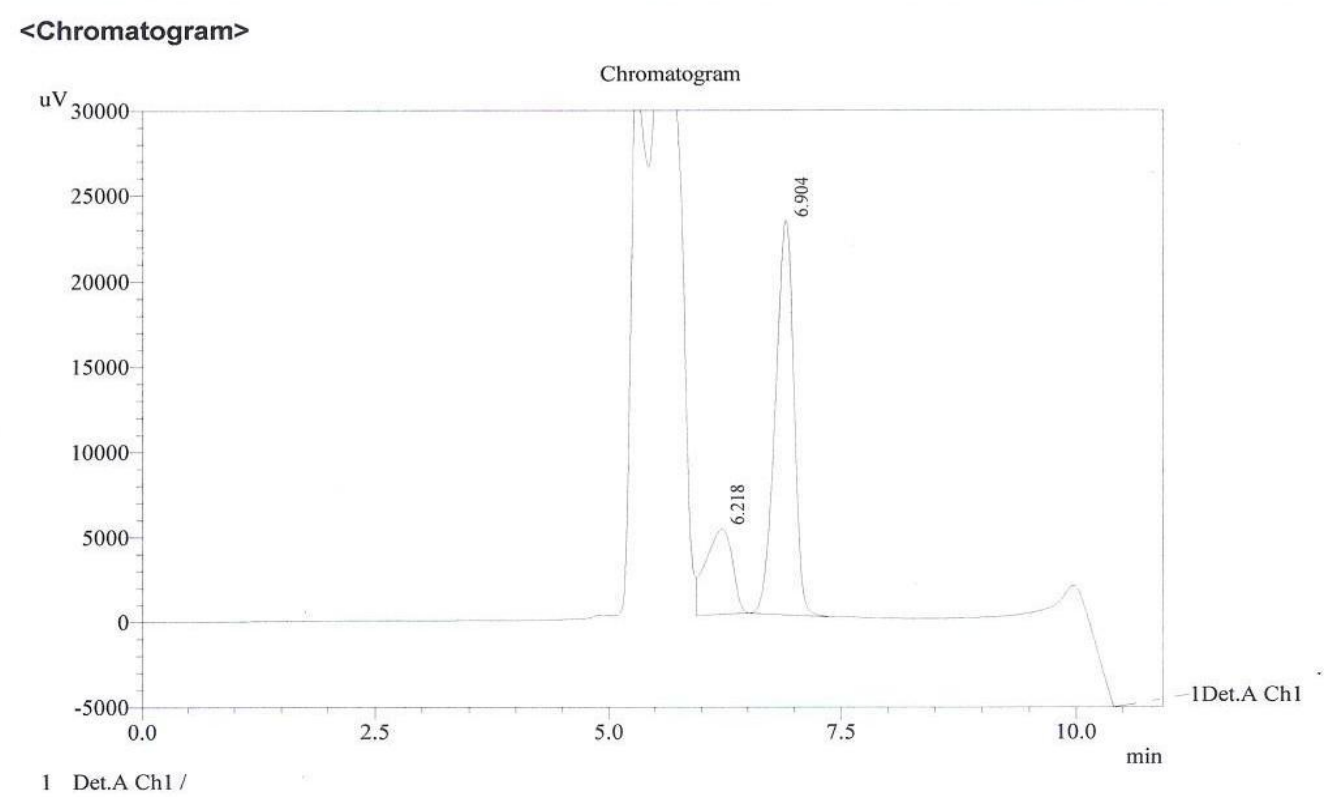

Fig.4 HPLC chromatographic peak showing the production of 1, 3-propanediol by Enterobacter cloacae GNTEW-13-V

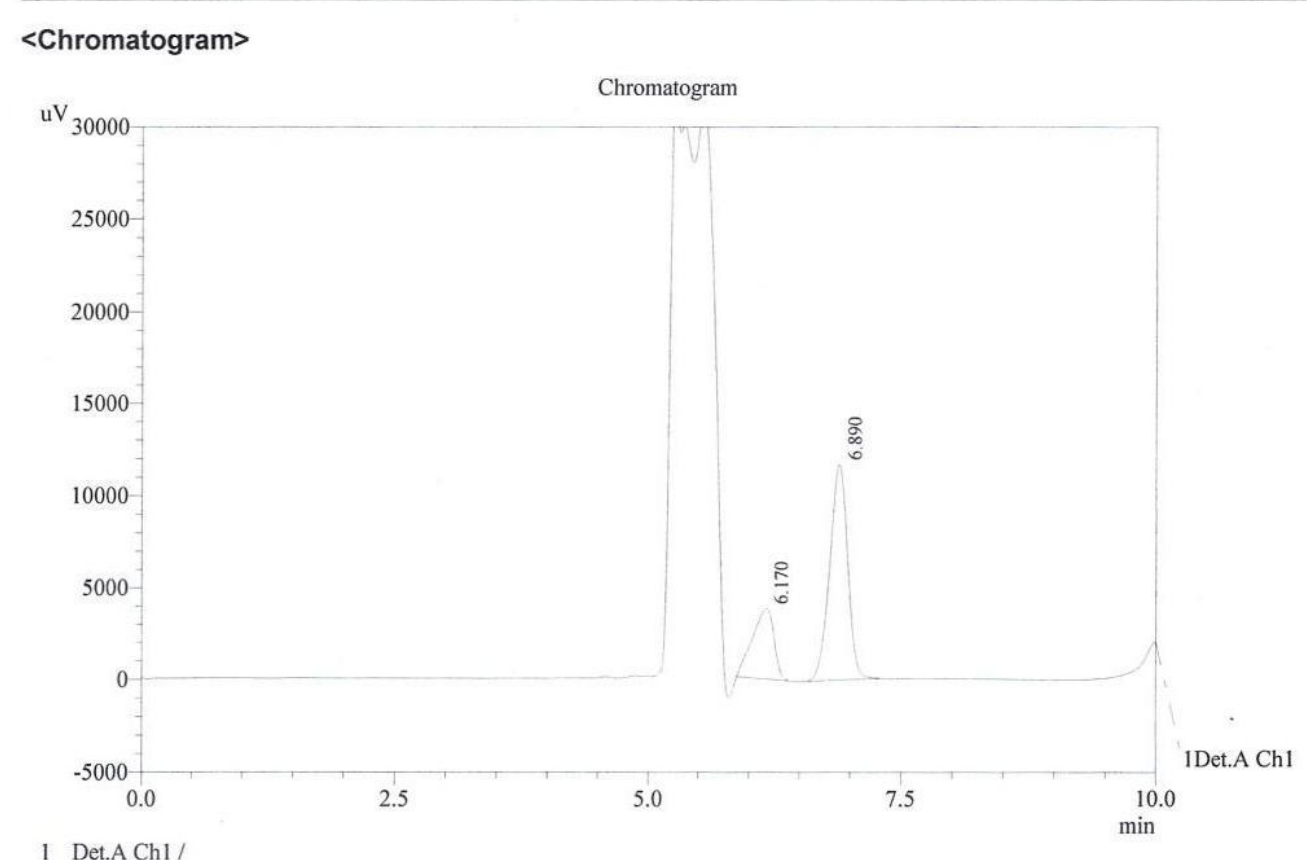

The Newly isolated strain Enterobacter Cloacae GNTEW-13-1 \& GNTEW-13-V has the good potentiality to produce 1, 3- propanediol, with the final concentration of $15.01 \mathrm{mg} / \mathrm{ml}$ and $14.99 \mathrm{mg} / \mathrm{ml}$ of $1,3-\mathrm{PDO}$ (Figure 1 \& Figure 1). However, all 
byproducts are associated with a loss in 1, 3PDO relative to acetic acid (Zeng and Biebl, 2002). A very important parameter that can affect 1, 3-PDO yield is $\mathrm{pH}$. The initial $\mathrm{pH}$ of culture medium was been found to be 7.0, but the $\mathrm{pH}$ considerably reduced after $24 \mathrm{~h}$ of fermentation experiment, reaching to 4.15. These changes may be probably due to the production of some organic acids during the fermentation time.

In the present study the newly isolated Enterobacter cloacae GNTEW-13-1 and Enterobacter cloacae GNTEW-13-V has the potentiality to utilize the biofuel derived crude glycerol as a sole carbon source to produce 1, 3-propanediol with higher yield.

The final concentration of the 1, 3propanediol produced by Enterobacter cloacae GNTEW-13-1 and Enterobacter cloacae GNTEW-13-V is $15.01 \mathrm{gm} / \mathrm{ml}$ and $14.99 \mathrm{gm} / \mathrm{ml}$ respectively.

However it is very much important to carry out some of the new experiments by optimizing the strain in order to increase the yield and high productivity of 1, 3propanediol than the present.

1, 3-propanediol production was enhanced when Enterobacter cloacae GNTEW-13-1 and Enterobacter cloacae GNTEW-13-V was subjected to mutagenesis with UV mutagens at sub lethal concentrations. Table .2 , summarizes the production of 1, 3propanediol by UV mutants. Among which the UV Mutant 6 had shown the maximum 1, 3-PDO production of $16.8 \mathrm{mg} / \mathrm{ml}$ over the parent strain $(15.01 \mathrm{mg} / \mathrm{ml})$.

\section{Acknowledgement}

The Authors are thankful to the department of Biotechnology Gulbarga University Gulbarga for providing the laboratory facility to carry the experimentations.

\section{References}

Biebl, H., Menzel, K., Zeng, A.P., Deckwer, W.D. 1999. Microbial production of 1,3-propandiol. Appl. Microbiol. Biotechnol., 52: 289-97.

Biebl, H. 2001. Fermentation of glycerol by Clostridium pasteurianum batch and continuous culture studies. J. Ind. Microbiol. Bitechnol., 27: 18-26.

Cameron, D.C., Altaras, N.E., Hoffman, M.L., Straw, A.J. 1998. Metabolic engineering of propanediol pathways. Biotechnol. Prog., 14: 116-25.

Cheng, K.K., Zhang, J.A., Liu, D.H., Sun, Y., Liu, H.J., Yand, M.D. 2007. Pilotscale production of 1,3-propaanediol using klebsiella pneumoniae. Process Biochem., 42: 740-4.

Dharmadi, Y., Murarka, A., Gonzalez, R. 2006. Anaerobic fermentation of glycerol by Escherichia coli: a new platform for metabolic engineering. Biotechnol. Bioeng., 94: 821-9.

Festal capital. 2007. (available on http://www.festel.com).

Forage, R., Lin, E.C.C. 1982. Dha system mediating aerobic and anaerobic dissimilation of glycerol in Klebsiella pneumonia NCIB418. J. Bacteriol., 15: 591-9.

Freund, A. 1881. UE ber die bildung darstellung von Trimethylenalkohol and glycerin. Monatsh Chem., 2: 63641.

Hao, J., Lin, R., Zheng, Z., Liu, H., Liu, D. 2008. Isolation and characterization of microorganisms able tp produce 1,3propandiol under aerobic conditions. World J. Microbiol. Biotechnol., 24: 1731-40.

Homann, T., Tag, C., Biebl, H., Deckwer, W.D., Schink, B. Fermentation of glycerol to 1,3-propandiolby 
Klebsiella and Citrobacter strains. Appl. Microbiol. Biotechnol., 33: 1216.

Mickelson, M.N., Werkman, C.H. 1940. Formation of trimethyleneglycol from glycerol by Aerobacter. Enzymologia, 8: $252-6$

Nakas, J.P., Schaedle, M., Parkinson, C.M., Coonley, C.E., Tanenbaum, S.W. 1983. System development for linkedfermentation products of solvents from algal biomass. Appl. Environ. Microbiol., 46: 1017-23.

Papanikolaou, S., Fick, M., Aggelis, G. 2004. The effect of raw glycerol concentration on the production of 1,3-propanediol by Clostridium butyricum. J. Chem. Technol. Biotechnol., 79: 1189-96.

Peng, Q.L., Dileme, F.B., Puhan, Z. 2002. effect of glucose on glycerol bioconversion by Lactobacillus reuteri. Appl. Microbiol. Biotechnol., 59: 289-96.

Sauer, M., Marx, H., Mattanovich, D. 2008. Microbial production of 1,3propanediol. Recent patents on Biotechnol, 2: 191-7.

Tong, L.T., Cameron, D.C. 1992. Enhancement of 1,3-propanediol production by cofermentation in Escherichia coli expressing genes from Klebsiella penumoniae dha regulon genes. Appl. Biochem. Biotechnol., 34/35: 149-59.

Waghmare, T., Naik, G.R. 2015. Chemical analysis of seed and oil of Jatropha curcas: A Biofuel Plant Cultivated in Hyderabad Karnataka Region, North karnataka. Int. J. Appl. Biol. Pharm. Technol., 6(1): 186-192.

Xiu, Z.L., Chen, X., Sun, Y.Q., Zhang, D.J. 2007. Stoichiometric analysis and experimental investigation of glycerolglucose cofermentation in Klebsiella pneumoniae under microaerobic conditions. Biochem. Eng. J., 33: 4252.

Yang, G., Tian, J., Li, J. 2007. Fermentation of 1,3-propanediol by Klebsiella oxytoca under microaerobic conditions. Appl. Microbiol. Biotechnol., 73: 1017-24.

Zend, A.P., Biebl, H. 2002. Bulk chemicals from Biotechnology: the case of 1,3propanediol production and the new trends. In: Scheper T, editor. $A d v$. Biochem. Engi. Biotechnol., vol. 74. Heidelberg: Springer Berlin;2002. p.239-59.

Zhu, M.M., Lawman, P.D., Cameron, D.C. 2002. Improving 1,3-propanediol production from glycerol in a metabolically engineered Escherichia coli by reducing accumulation of snglycerol-3-phosphate. Biotechnol. Prog., 18: 694-9.

\section{How to cite this article:}

Tathagat Waghmare and G.R. Naik. 2016. Microbial Production of 1, 3-Propanediol using Newly Isolated Enterobacter cloacae GNTEW13-1, GNTEW13-V and its Enhancement Studies by UV Mutagenesis. Int.J.Curr.Microbiol.App.Sci. 5(7): 953-960. doi: http://dx.doi.org/10.20546/ijcmas.2016.507.107. 